\title{
ANÁLISE DE CRESCIMENTO E TROCAS GASOSAS NA CULTURA DE MILHO EM PLANTIO DIRETO E CONVENCIONAL $\left({ }^{1}\right)$
}

\author{
JOÃO PAULO LOPES $\left({ }^{2}\right)$; EDUARDO CARUSO MACHADO $\left(3,4^{*}\right)$; ROBERT DEUBER $\left({ }^{3}\right)$; \\ RICARDO SILVERIO MACHADO $\left({ }^{2}\right)$
}

\begin{abstract}
RESUMO
O sistema de plantio exerce efeitos característicos sobre o solo e pode afetar o crescimento das plantas. Neste trabalho se avaliou, por meio de análise de crescimento e de trocas gasosas os efeitos do plantio direto (PD) e plantio convencional (PC) na cultura de milho após cultivo de triticale. O delineamento experimental foi em blocos ao acaso com parcelas (sistema de plantio) subdivididas (datas de coletas) com seis repetições. Os dados primários de massa seca e área foliar foram obtidos em plantas cortadas ao nível do solo em intervalos de 15 dias. Calcularam-se a taxa de crescimento da cultura (TCC), taxa de assimilação líquida (TAL) e o índice de área foliar $(I A F)$. As medidas de trocas gasosas [assimilação de $\mathrm{CO}_{2}(A)$; transpiração $(E)$ e condutância estomática $(g s)$ ] foram efetuadas com um analisador portátil de fotossíntese, aos 36, 49 e 80 dias após a emergência, respectivamente nos estádios $\mathrm{V}_{8}$ (desenvolvimento vegetativo), $\mathrm{V}_{\mathrm{T}}$ (pendoamento) e $\mathrm{R}_{4}$ (grãos pastosos). IAF, TCC, a fitomassa seca total, das espigas, dos colmos e a produtividade de grãos foram superiores em PC. As trocas gasosas não apresentaram diferenças entre os sistemas de plantio. A ocorrência de deficiência hídrica em fevereiro e em março causou decréscimos em $A$, gs e $E$. As diferenças observadas em PC foram relacionadas ao desenvolvimento mais rápido e maior do $I A F$.
\end{abstract}

Palavras-chave: crescimento; fotossíntese; sistema de produção; Zea mays; X Triticosecale.

\section{ABSTRACT \\ GROWTH ANALYSIS AND GAS EXCHANGES IN CORN CULTIVATED IN NO TILLAGE AND CONVENTIONAL CROPPING}

Each cropping system acts in a particular way on soil characteristics and may affect crop growth differently. In this research the effects of no tillage (NT) and conventional system (CS) on corn cultivated after triticale, were evaluated by using growth analysis and gas exchanges. The experimental design was completely randomized block with plots (cropping system) and sub-plots (sampling dates) with six replications. The primary data of dry matter and leaf area were collected from all plants in one meter row which were, cut at the level of the soil, every 15 days. Crop growth rate (CGR), net assimilation rate $(N A R)$ and leaf area index $(L A I)$ rate were evaluated. Measurements of gas exchanges $\left[\mathrm{CO}_{2}\right.$ assimilation $(A)$; transpiration $(E)$ and stomatic conductance $(g s)]$ were take using photosynthesis a portable analyzer at 36,49 , and 80 days after the seedling emergence, at the stage $\mathrm{V}_{8}, \mathrm{~V}_{\mathrm{T}}$ and $\mathrm{R}_{4}$, respectively. LAI and $C G R$, total dry matter, dry matter of stems, ears and grains were higher in CS. The gas exchanges did not showed any differences between the cropping systems. The occurrence of water deficiency in February and March causes reduction of $A, g s$ and $E$. The differences observed in CS were related to the faster growth and higher $L A I$.

Key words: plant growth, photosynthesis, cropping systems, Zea mays ; X Triticosecale.

( $\left.{ }^{1}\right)$ Recebido para publicação em 19 de maio de 2008 e aceito em 10 de junho de 2009.

$\left({ }^{2}\right)$ Curso de Pós-graduação em Agricultura Tropical e Subtropical do Instituto Agronômico (IAC), Caixa Postal 28, $13012-970$ Campinas (SP). E-mail: joaolopes2@uol.com.br

$\left({ }^{3}\right)$ Centro de Pesquisa e Desenvolvimento em Ecofisiologia e Biofísica do IAC. E-mail: caruso@iac.sp.gov.br (*) Autor correspondente; rdeuber@iac.sp.gov.br

$\left({ }^{4}\right)$ Bolsista em Produtividade Científica do CNPq. 


\section{INTRODUÇÃO}

O plantio direto reduz a mobilização do solo e mantém a cobertura morta da cultura anterior sobre a superfície do solo. A semeadura revolve o solo apenas na linha de plantio, onde são depositadas as sementes e fertilizantes. As plantas infestantes são controladas com uso de herbicidas que não exigem incorporação. Esse sistema de manejo é eficiente no controle da erosão. A cobertura morta protege a superfície do solo contra o impacto das gotas de chuva, reduzindo a desagregação e a impermeabilização da superfície, favorecendo a infiltração da água no solo e diminuindo, com isso, o arraste de partículas (Mello e Silva., 1993).

Além dos efeitos sobre o solo, o plantio direto afeta o crescimento da planta em função da alteração do ambiente. Muitos trabalhos que comparam o plantio direto e convencional avaliam somente a produtividade final das culturas e as características e propriedades do solo (Mello e Silva, 1993; Yusuf et al., 1999; Pedersen e Lauer, 2003; Qin et al., 2005). Em relação à produtividade da cultura, os resultados são muitas vezes contraditórios. Observam-se tanto produtividades maiores sob plantio direto $(P D)$ quanto sob plantio convencional $(P C)$, além de ocorrer muitas vezes valores semelhantes (HiLL, 1990; Ismail et al., 1994; Hernani e Salton, 1997; Pauletti et al., 2003; Silveira e Stone, 2003; Carvalho et al., 2004; SECCO et al., 2005). Tais controvérsias podem estar relacionadas a vários fatores, como ocorrência de estresse hídrico, altas temperaturas, adubações diferentes e outros que interferem paralelamente no desenvolvimento vegetal (Cox et al.,1990; Pedersen e Lauer, 2003; CARVAlho et al., 2004; Singer et al., 2007).

Há trabalhos que analisam os efeitos destes sistemas de manejo diretamente sobre as plantas, indicando que mesmo sob produtividades semelhantes, podem existir diferenças no padrão de crescimento e desenvolvimento inicial da cultura (Yusuf et al., 1999).

Segundo URCheI et al. (2000), por meio da análise quantitativa do crescimento podem-se avaliar os efeitos de sistemas de manejo sobre as plantas, pois se descreve as mudanças nas características do crescimento em função do tempo, o que não é possível com o simples registro do rendimento. A análise quantitativa do crescimento é um método que acompanha a dinâmica da produção fotossintética e representa a referência inicial na análise de produção, requerendo informações que podem ser obtidas sem a necessidade de equipamentos sofisticados (PereIrA e MACHADO, 1987).
A agricultura é basicamente um sistema de exploração da energia solar por meio da fotossíntese, visto que este processo é responsável pelo acúmulo de toda a matéria orgânica das plantas. Qualquer fator que interfira na eficiência deste processo interferirá no desenvolvimento da planta.

Têm-se como hipótese que o sistema de plantio afeta as condições físicas, químicas e biológicas do solo, afetando o padrão de crescimento, as trocas gasosas e a produtividade da cultura de milho. Neste trabalho, teve-se como objetivo estudar o crescimento e as trocas gasosas da planta de milho em seqüência ao triticale nos sistemas de plantio direto e convencional.

\section{MATERIAL E MÉTODOS}

O experimento foi realizado em Campinas (SP) a $22^{\circ} 54^{\prime} \mathrm{S}, 47^{\circ} 03^{\prime} \mathrm{W}$, em uma área de $40 \times 60 \mathrm{~m}$, com leve declive, altitude $674 \mathrm{~m}$ em Latossolo Vermelho Distroférrico típico (EMBRAPA, 1999). O clima, de acordo com a classificação climática de Köppen, é do tipo Cwa (Setzer, 1966).

Foi semeado o triticale (X Triticosecale) em área total e na seqüência, após a colheita, o mesmo campo experimental foi cultivado com milho híbrido IAC8333 (Zea mays L.). Em uma faixa do terreno o solo foi preparado com uma aração (aiveca), duas gradagens com grade pesada e, posteriormente, com grade niveladora. Na outra faixa, não houve movimentação do solo. O triticale foi cultivado com o objetivo de formar uma camada de fitomassa sobre o solo (cobertura morta). Foram realizados dois tratamentos: 1) plantio no sistema direto (PD) e 2) plantio no sistema convencional (PC). A parcela utilizada para o PD do milharal foi a mesma do plantio direto de triticale. O mesmo critério foi utilizado para o PC. Na área total foi aplicado herbicida glifosato na dosagem $2 \mathrm{~L} \mathrm{ha}^{-1}$ de Roundup (p.c.) uma semana antes da semeadura. Em 25/1/2007 foi aplicado a mistura dos herbicidas pós-emergentes nicosulfuron, Sanson (p.c.) e 2,4-D, 2,4-D Fluid (p.c.) nas dosagens de $75 \mathrm{~mL} \mathrm{ha}^{-1}$ e $70 \mathrm{~mL} \mathrm{ha}^{-1}$ respectivamente.

O milharal foi semeado no dia 13/12/2006, no espaçamento de $0,90 \mathrm{~m}$ com sete sementes por metro linear atingindo uma população de 65.000 plantas $\mathrm{ha}^{-1}$. Nas duas parcelas, tanto de PD como PC, a semeadura foi efetuada com semeadora/adubadora (Semeato PS-M) própria para plantio direto. A regulagem usada na semeadora/adubadora foi a mesma nos dois tratamentos, logo a área de PC, onde o solo foi revolvido e teve sua estrutura desagregada, o peso da máquina fez com que a semente ficasse um pouco mais profunda, porém, a emergência das 
plantas ocorreu na mesma data, isto é, ao redor de sete dias após a semeadura. O milharal foi adubado com $236 \mathrm{~kg} \mathrm{ha}{ }^{-1}$ do formulado (N-P-K) 08-28-16. Posteriormente, 30 dias após a emergência (DAE) adubou-se com $100 \mathrm{~kg}$ de uréia ha ${ }^{-1}$.

O delineamento experimental foi em blocos ao acaso, no esquema de parcelas subdivididas no tempo, com seis repetições. Nas parcelas principais, foram aplicados os dois tratamentos: PD e PC. Cada parcela foi dividida em 10 subparcelas, nas quais foram efetuadas as coletas destrutivas periódicas de plantas para análise quantitativa do crescimento. Cada parcela media $10 \mathrm{~m}$ de largura por $30 \mathrm{~m}$ de comprimento e a subparcela $10 \mathrm{~m} \times 3 \mathrm{~m}$.

A produtividade final foi avaliada a partir da colheita das espigas contidas em duas linhas com 5 $m$ em cada repetição. Os grãos foram separados das espigas e pesados, após secagem por sete dias em estufa com circulação forçada de ar a $70{ }^{\circ} \mathrm{C}$.

Para a avaliação da fitomassa seca e da área foliar foram realizadas oito coletas, uma em cada subparcela. Cada coleta constou do corte, na altura do colo, da parte aérea de todas as plantas contidas em 1,0 $\mathrm{m}$ linear. As coletas destrutivas foram iniciadas
$30 \mathrm{DAE}$, sendo repetidas em intervalos de 15 dias até a maturação fisiológica.

As plantas depois de colhidas foram levadas ao laboratório e separadas em folha, colmo e espiga, para avaliação da fitomassa seca das diversas partes da planta separadamente. A fitomassa seca foi medida após secagem em estufa com circulação de ar forçada por sete dias a $70{ }^{\circ} \mathrm{C}$. Antes da secagem, mediu-se a área individual de cada folha da amostra utilizando-se um integrador de área, Li-3100 (Licor Inc. Lincoln-EUA).

Os dados primários (fitomassa seca total, das espigas, das folhas e dos colmos e o índice de área foliar) e da produtividade de grãos foram submetidos à análise de variância e as médias comparadas pelo teste de Tukey a 5\% de probabilidade, quando detectada diferença significativa entre os tratamentos.

Para descrever o acúmulo de fitomassa seca total $(Y)$ e das espigas $(E)$ utilizou-se a função de Boltzmann e para o índice de área foliar (IAF) a função de Gauss. Os ajustes de curvas foram obtidos utilizando-se o programa Origin 7.5 e os coeficientes de ajuste são apresentados nas tabelas 1 e 2 . Os seguintes índices fisiológicos foram calculados a partir das curvas ajustadas, segundo BEADLE (1993):

Tabela 1. Coeficientes das funções de Boltzmann $\left(F=A 2+(A 1-A 2) /\left(1+\exp \left(\left(x-x_{0}\right) / d_{x}\right)\right)\right.$ selecionadas para descrever o acúmulo de fitomassa seca total e de espigas em milho híbrido IAC-8333 cultivado no sistema de plantio direto (PD) e plantio convencional (PC)

\begin{tabular}{|c|c|c|c|c|}
\hline \multirow{2}{*}{ Coeficientes } & \multicolumn{2}{|c|}{ Fitomassa seca total } & \multicolumn{2}{|c|}{ Fitomassa seca das espigas } \\
\hline & PC & PD & $\mathrm{PC}$ & PD \\
\hline & 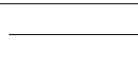 & 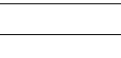 & & \\
\hline A1 & 86,96 & 23,30 & $-6299,84$ & $-83,60$ \\
\hline $\mathrm{A} 2$ & 1338,08 & 987,38 & 756,07 & 605,97 \\
\hline$x_{0}$ & 66,39 & 69,06 & 29,72 & 79,24 \\
\hline$d_{x}$ & 5,99 & 6,71 & 14,27 & 9,86 \\
\hline $\mathrm{R}^{2}$ & 0,98 & 0,99 & 0,99 & 0,99 \\
\hline
\end{tabular}

Tabela 2. Coeficientes das funções de Gauss (IAF $=y_{0}+$ $(\mathrm{A} /(\mathrm{w} \sqrt{\pi / 2})) \exp \left(-2\left(\left(\mathrm{x}-\mathrm{x}_{0}\right) / \mathrm{w}\right)^{2}\right)$ selecionadas para descrever o índice de área foliar em milho híbrido IAC8333 cultivado no sistema de plantio direto (PD) e plantio convencional (PC)

\begin{tabular}{|c|c|c|}
\hline \multirow{2}{*}{ Coeficientes } & \multicolumn{2}{|c|}{ Índice de área foliar } \\
\hline & PC & PD \\
\hline & \multicolumn{2}{|c|}{$\mathrm{m}^{2} \mathrm{~m}^{-2}$} \\
\hline $\mathrm{y}_{\mathrm{o}}$ & $-0,698$ & $-1,282$ \\
\hline$x_{0}$ & 69,49 & 60,20 \\
\hline $\mathrm{w}$ & 61,44 & 61,16 \\
\hline A & 538,38 & 682,15 \\
\hline $\mathrm{R}^{2}$ & 0,96 & 0,97 \\
\hline
\end{tabular}

a) taxa de crescimento da cultura (TCC) dada por:

$$
T C C=d Y / d t \quad\left[\mathrm{~g} \mathrm{~m}^{-2} \text { de terreno } \mathrm{d}^{-1}\right]
$$

em que $d Y / d t$ indica a derivada do acúmulo de fitomassa seca $(Y)$ pelo tempo.

b) Taxa de assimilação líquida (TAL) obtida pela relação entre a TCC e o IAF:

$$
T A L=(1 / I A F . d Y / d t) \quad\left[\mathrm{g} \mathrm{m}^{-2} \text { área foliar } \mathrm{d}^{-1}\right] .
$$

c) Índice de área foliar $(I A F)$, área foliar em relação à área de terreno $(S)$ ocupada, dada pela equação,

$$
I A F=A F / S \quad\left[\mathrm{~m}^{2} \mathrm{~m}^{-2}\right]
$$


em que $A F$ é á área das folhas $\mathrm{em}^{2}$ contidas em 1 $\mathrm{m}^{2}$ de terreno ocupado pela cultura.

As medidas de trocas gasosas foram realizadas em três ocasiões: em $24 / 1 / 2007$, em $7 / 2$ / 2007 e em 8/3/2007, respectivamente, nos estádios de desenvolvimento $V_{8}$ (desenvolvimento vegetativo), $V_{T}$ (pendão completamente visível) e $\mathrm{R}_{4}$ (grão pastosos) (MAGAlHÃEs et al., 2003).

As variáveis assimilação líquida de $\mathrm{CO}_{2}(A)$, transpiração $(E)$, condutância estomática $(g s)$ e a diferença de pressão de vapor entre a folha e o ar $\left(D P V_{\text {folha-ar }}\right)$, foram medidas com o equipamento portátil de fotossíntese modelo LI-6400 (Licor Inc. Lincoln, NE), que mede a concentração de $\mathrm{CO}_{2}$ e de vapor de água, por radiação infravermelha. $\mathrm{O}$ equipamento ainda mede, e permite controlar, o microclima [temperatura da folha $\left(T_{\text {folha }}\right)$ e do ar, umidade relativa e pressão de vapor] e a densidade de fluxo de fótons fotossinteticamente ativos (DFFFA) dentro da câmara de medida, que abrange uma área foliar de $6 \mathrm{~cm}^{2}(2 \times 3 \mathrm{~cm})$.

As medidas foram executadas sob condições naturais em dias limpos, no período entre 7 e $17 \mathrm{~h}$ em intervalos de aproximadamente 2 horas, com cinco repetições. Na $1 .^{a}$ ocasião de medidas, utilizou-se a folha mais desenvolvida e nas $2 .^{a}$ e $3 .^{a}$ medidas utilizou-se a folha bandeira. A fim de homogeneizar as repetições, a DFFFA foi gerada por um diodo emissor de luz acoplado à câmara de fotossíntese, no valor igual ao medido pelo quantômetro do equipamento para cada horário.

O balanço hídrico climatológico decendial para o período entre novembro de 2006 e junho de 2007 $(\mathrm{CAD}=100 \mathrm{~mm})$ foi calculado com a utilização da planilha eletrônica desenvolvida por RoLIM et al., (1998), utilizando-se dados meteorológicos fornecidos pelo Centro Integrado de Informações Agrometeorológicas (CIIAGRO, http:// www.ciiagro.sp.gov.br), do Instituto Agronômico (IAC), em Campinas (SP).

\section{RESULTADOS E DISCUSSÃO}

No ano agrícola de 2006/2007, ocorreu déficit hídrico nos dois últimos decêndios em fevereiro (Figura 1), coincidindo com o pós-florescimento e, posteriormente, em meados de março e de abril, coincidindo com o meio e o fim do período de enchimento de grãos respectivamente. Em fevereiro, foram registradas temperaturas máximas que ultrapassaram $30{ }^{\circ} \mathrm{C}$ e mínimas próximas a $20{ }^{\circ} \mathrm{C}$. As temperaturas médias em janeiro, fevereiro e março de 2007 foram $25,1^{\circ} \mathrm{C}, 25,7^{\circ} \mathrm{C}$ e $24,2^{\circ} \mathrm{C}$ respectivamente, sendo ao redor de $2^{\circ} \mathrm{C}$ acima da média normal, segundo CiIAGro.
Observou-se no milharal $50 \%$ de pendoamento aos 50 DAE $\left(V_{\mathrm{T}}\right)$, começando a fase de formação de espiga e crescimento de grãos próximo aos $60 \mathrm{DAE}$, ocorrido na primeira quinzena de fevereiro.

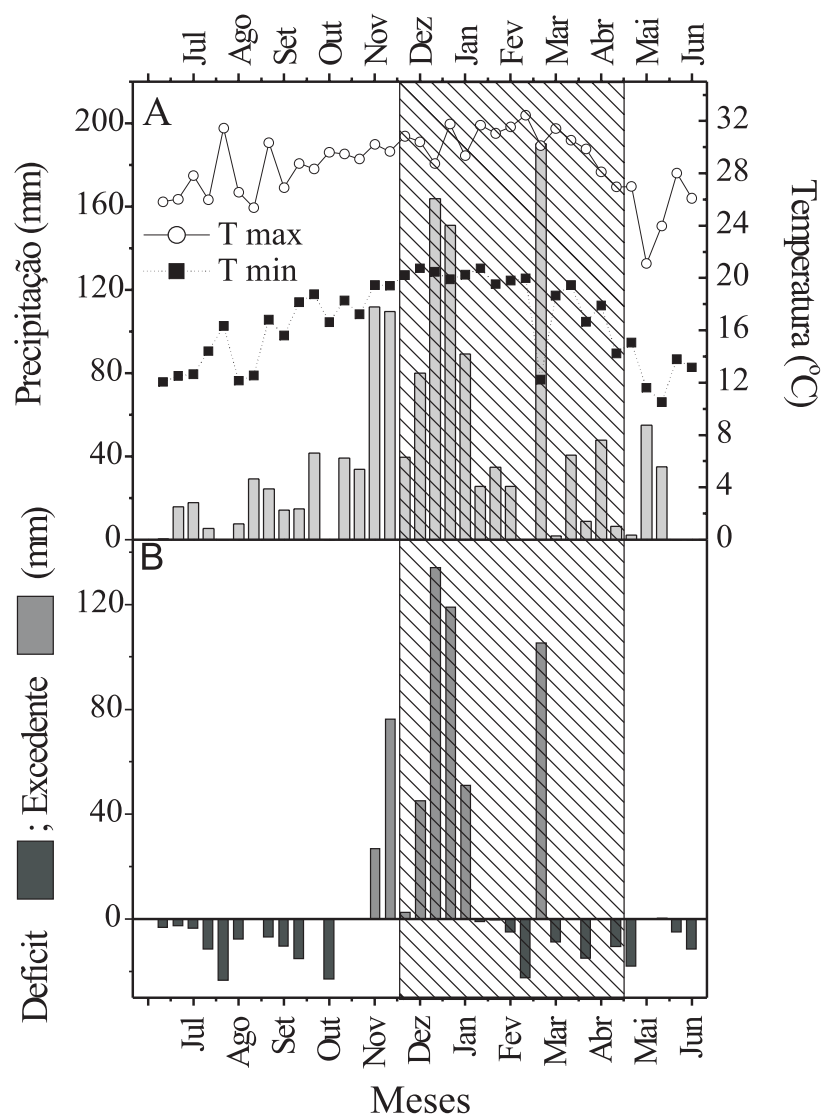

Figura 1. Temperatura do ar e precipitação pluvial (A) e extrato do balanço hídrico (B) de 2006/2007 em Campinas (SP), calculado segundo Thornthwaite e Mather (1955), utilizando planilha eletrônica desenvolvida por Rolim et al. (1998). Capacidade de água disponível (CAD) de $100 \mathrm{~mm}$. Área hachurada indica o período experimental que foi de dezembro de 2006 a abril de 2007. Os cálculos foram realizados a partir de dados obtidos em estação meteorológica localizada a $500 \mathrm{~m}$ do campo experimental (CIIAGRO/ IAC).

O valor máximo de fitomassa seca das folhas ocorreu por volta de 90 DAE nos dois sistemas de plantio, sendo $18,9 \%$ maior no sistema PC em relação ao PD (Figura 2C). O crescimento máximo das espigas foi atingido aos $135 \mathrm{DAE}$, sendo significativamente maior em PC em relação a PD (Figura 2D). Outros autores também observaram maior crescimento de espigas e/ou produção de grãos em PC (PAUletti, 2003; Carvalho, 2004). No entanto, nem sempre os resultados relativos à produtividade são semelhantes, havendo relatos em que a maior produtividade ocorreu em PD (Mello e Silva, 1993; URCheI et al., 2000; Pedersen e Lauer, 2003). 

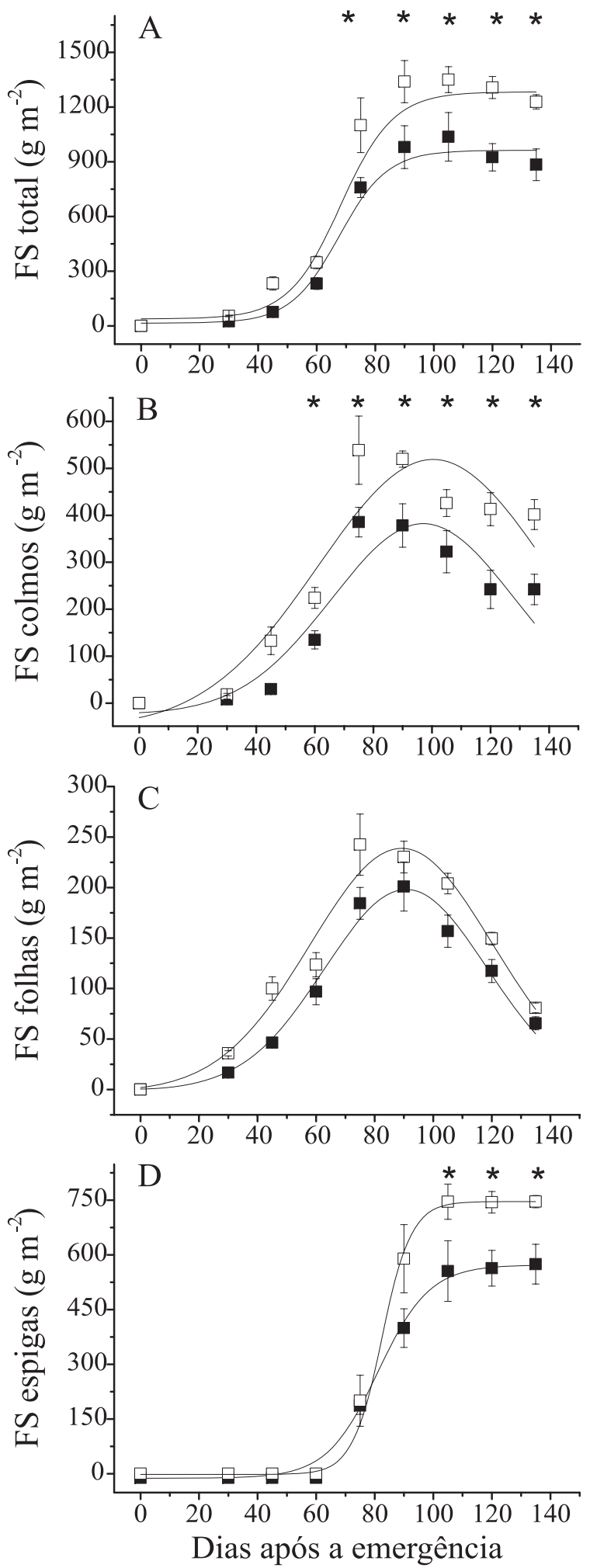

Figura 2. Acúmulo de fitomassa seca (FS) total (A), nos colmos (B), nas folhas (C) e nas espigas (D) em função do número de dias após a emergência em milho híbrido IAC-8333 cultivado no sistema de plantio direto $(\boldsymbol{\square})$ e plantio convencional ( $\square$ ). Pontos indicam média de seis repetições, barras desvio-padrão e asterisco (*) diferença estatisticamente significativa pelo teste Tukey ao nível de 5\% no ponto indicado.
A fitomassa seca de colmo em PC foi significativamente maior que em PD a partir da 2 a $^{\text {a }}$ coleta (45 DAE) atingindo valores máximos de 527,0 e $367,8 \mathrm{~g} \mathrm{~m}^{-2}$, respectivamente, ao redor do $90^{\circ} \mathrm{DAE}$ para depois decair progressivamente até o fim do ciclo (Figura 2B).

A fitomassa total da planta foi significativamente maior em PC, principalmente a partir de 60 DAE, logo após o pendoamento das plantas (Figura 2A). Outros autores (CENTURION e Demattê, 1985; Carvalho et al., 2004; Singer et al., 2007) também observaram maior acúmulo de fitomassa total em PC em relação ao PD; em anos com deficiência hídrica, o desempenho em PC foi relativamente melhor. Estes autores sugeriram que o melhor desempenho da cultura no sistema PC, talvez esteja relacionado ao desenvolvimento do sistema radicular. A mobilização do solo causa diminuição da densidade na camada arável podendo favorecer o crescimento inicial das raízes. O maior crescimento de raiz proporcionaria maior tolerância a um período de estiagem (Mello e Silva, 1993; Qin et al., 2005). No entanto, há controvérsias em relação a esses resultados, pois há também autores que citam vantagens do crescimento de milho em cultivos com PD devido à melhor conservação da água (Cox et al.,1990; Mello e Silva, 1993; Pedersen e Lauer, 2003; Carvalho et al., 2004). Portanto, este é um ponto que deve ser mais bem esclarecido e estudado. Possivelmente, resultados conflitantes poderão ser esclarecidos com estudo mais detalhados que considerem conjuntamente o crescimento aéreo e radicular da planta, incluindo avaliações do índice de colheita (massa de grãos/ massa da fitomassa total), caracterização do solo e do ambiente. O maior valor de fitomassa seca total ocorreu aos 90 DAE em PC e aos 105 DAE em PD. Após essas datas, nos dois sistemas, o acúmulo de fitomassa seca total praticamente cessou, apesar de haver crescimento significativo das espigas (Figura 2D), porém houve também queda de folhas e da massa nos colmos (Figura 2B,C). A queda na fitomassa seca de folha ocorreu devido ao início da senescência, enquanto a queda na massa dos colmos deve estar associada à transferência de carboidratos para outros órgãos em crescimento, especificamente às espigas, como demonstraram MACHADO et al. (1982).

Em ambos os sistemas de plantio, inicialmente as TCCs foram baixas e posteriormente aumentaram até o máximo de 34,1 e 24,5 $\mathrm{g} \mathrm{m}^{-2} \mathrm{~d}^{-1}$ para PC e PD, respectivamente, pouco após o florescimento, entre 60 e 70 DAE (Figura 3A). Na sétima coleta, por volta de 105 DAE, as TCCs em ambos os sistemas ficaram negativas, devido à queda da fitomassa seca de folhas e colmo. No fim do ciclo o IAF (Figura 3C) cai devido à queda de folhas velhas, alterando a TCC. 


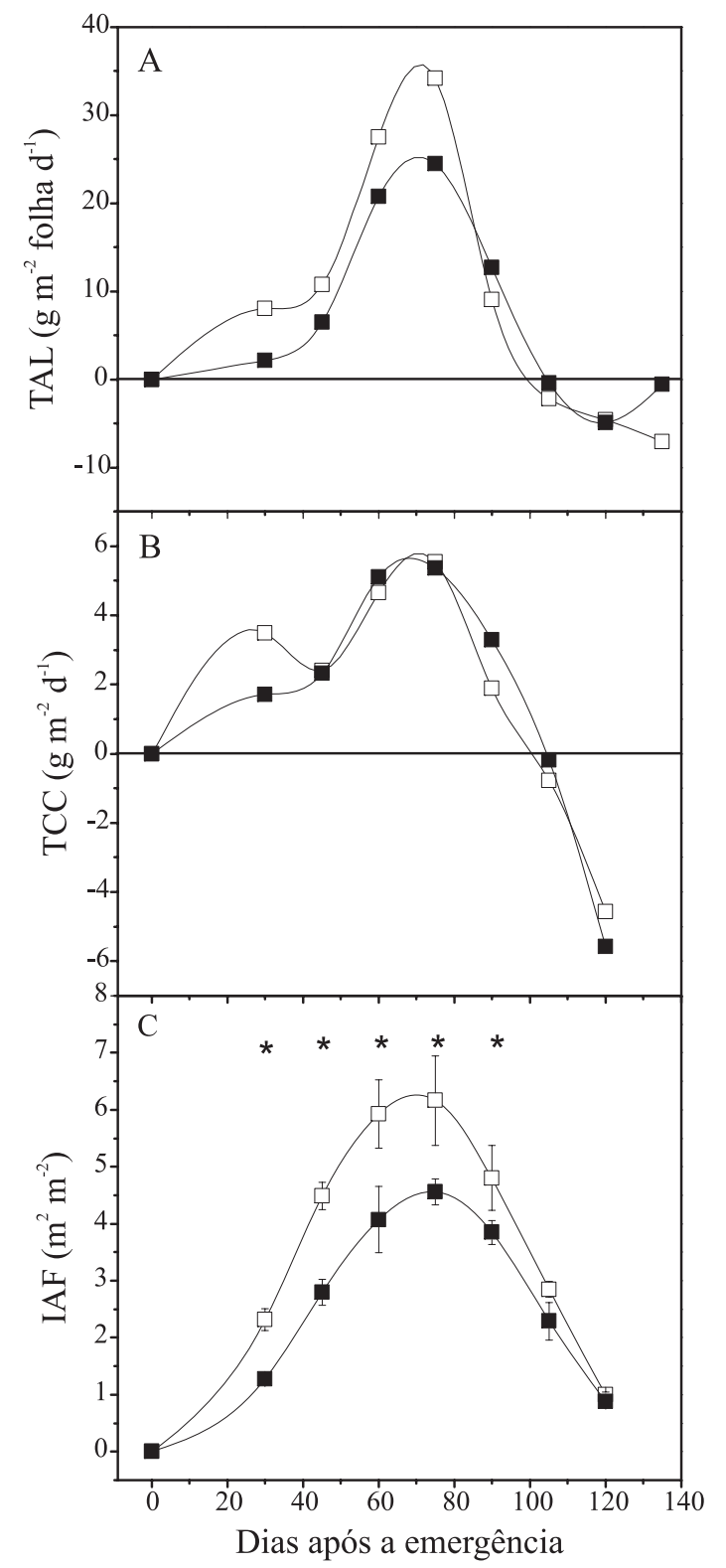

Figura 3. Taxa de crescimento da cultura, TCC (A), taxa de assimilação líquida, TAL (B) e índice de área foliar, IAF (C) em função do número de dias após a emergência em milho híbrido IAC-8333 cultivado no sistema de plantio direto $(\boldsymbol{\square})$ e plantio convencional $(\square)$. Na parte $C$ da figura os pontos indicam média de seis repetições, barras desvio-padrão e asterisco $\left(^{*}\right)$ diferença estatisticamente significativa pelo teste Tukey ao nível de 5\% no ponto indicado.

No IAF houve diferenças significativas entre os sistemas de plantio a partir da segunda coleta realizada com 45 DAE sendo maior em PC.

A TCC é definida pelo produto do IAF pela $T A L$, sendo, portanto o IAF interpretado como coeficiente entre TCC e TAL (BEADLE, 1993). As diferenças observadas em TCC entre os dois sistemas de plantio foram devidas principalmente às diferenças no IAF (Figura 3C). O IAF máximo ocorreu entre 60 e 75 DAE com valores de $6,2 \mathrm{~m}^{2} \mathrm{~m}^{-2}$ no PC e $4,7 \mathrm{~m}^{2} \mathrm{~m}^{-2}$ no PD (Figura 3C). Os maiores valores de TAL (Figura 3B) foram verificados entre a quarta e quinta coletas, entre 60 e $80 \mathrm{DAE}$, correspondendo o fim do florescimento e início de enchimento de grãos, respectivamente.

A TAL, nos dois sistemas de plantio, aumentou em resposta ao aumento da demanda por produtos fotoassimilados pelos órgãos reprodutivos, conforme também relataram outros autores (MACHADO et al., $1982,1985,1990)$. Após o florescimento e com o início da formação de espigas a $T A L$ reduziu.

No caso presente, o acúmulo de fitomassa da planta de milho foi maior no PC, possivelmente, devido ao maior desenvolvimento do IAF que propiciou maiores TCC, visto que TAL foi semelhante nos dois sistemas de plantio. O maior desenvolvimento do IAF talvez esteja relacionado com maior crescimento das raízes, que propiciaria maior absorção de água e de nutrientes, conforme observaram QIN et al. (2005). No entanto, no caso presente, o teor de nutrientes das folhas e a eficiência do uso de água (razão entre $A / E$ ) foram semelhantes entre os dois sistemas de plantio (dados não mostrados).

Além do maior acúmulo de fitomassa seca total e crescimento do $I A F$, também a produtividade de grãos foi significativamente maior em PC em relação a PD, ou seja, $8167 \mathrm{~kg} \mathrm{ha}^{-1}$ e $6180 \mathrm{~kg} \mathrm{ha}^{-1}$ respectivamente, representando uma diferença de $32,2 \%$.

Na figura 4 nota-se a variação diária de $D F F F A$, de $T_{\text {folha }}$ e da de $D P V_{\text {folha-ar }}$ para as três datas em que foram medidas as trocas gasosas. Não houve diferença em $T_{\text {folha }}$ DFFFA e em $D P V_{\text {folha-ar }}$ em relação ao sistema de plantio (Figura 4). Os valores máximos em $T_{\text {folha }}$ foram verificados ao redor das $14 \mathrm{~h}$, e no estádio $R_{4}(80 \mathrm{DAE})$ atingiu $41{ }^{\circ} \mathrm{C}$, superando as temperaturas máximas entre 33 e $35^{\circ} \mathrm{C}$ nos estádios $\mathrm{V}_{8}$ (36 DAE) e $\mathrm{V}_{\mathrm{T}}$ (49 DAE) respectivamente. Observouse na curva de $D P V_{\text {folha-ar }}$ um padrão semelhante à curva de $T_{\text {folhar }}$ sendo maiores valores verificados nos períodos mais quentes do dia. Em $D P V_{\text {folha-ar }}$ os valores mais elevados ocorreram na última data de medida de trocas gasosas, em $\mathrm{R}_{4}$. Nos primeiros decêndios de fevereiro e de março ocorreram déficits hídricos moderados no solo (Figura 1).

Nos três estádios de desenvolvimento do milharal, a variação diária de DFFFA seguiram um padrão semelhante, ou seja aumentaram rapidamente até um máximo no sentido do início da manhã até ao 
redor das $11 \mathrm{~h}$ (aproximadamente $2.000 \mu \mathrm{mol} \mathrm{m}^{-2} \mathrm{~s}^{-1}$ ) quando então variaram pouco até ao redor da $14 \mathrm{~h}$, para depois decaírem constantemente no período vespertino (Figura 4). Comparativamente, os valores de $T_{\text {folhar }}$ DFFFA e DP $V_{\text {folha-ar }}$ foram semelhantes para os dois sistemas de plantio, e seus efeitos sobre as variáveis relativas a trocas gasosas serão analisados em conjunto.

Praticamente, $A, g s$ e $E$ foram semelhantes para os dois tratamentos, ou seja, nesse experimento o tipo de plantio não afetou estas variáveis (Figura 5). Sob condições normais Cox et al. (1990) também observaram que o sistema de plantio não afetou $A$ em milho. Porém, sob estresse hídrico estes autores observaram que $A$ foi maior em PC (Cox et al., 1990). No nosso caso, ocorreu estresse hídrico com intensidade suficiente para causar queda em $A$ e $g s$ entre os períodos de medidas, mas não causou diferenças detectáveis devidas ao tipo de plantio. Assim, as diferenças observadas na TCC (Figura 3A) e na produção de espigas e grãos em favor de PC não foram devidas às variações em $A$. Possivelmente, como foi discutido anteriormente, o crescimento superior das plantas sob PC foi devido ao maior IAF (Figura 3A).

As variações diárias de $A$ nos estádios $\mathrm{V}_{8} \mathrm{e}$ $\mathrm{V}_{\mathrm{T}}$ (36 e 49 DAE) seguiram padrões semelhantes, iniciando com valores mais baixos no início da manhã, atingindo o máximo ao redor das $11 \mathrm{~h}$ e mantendo-se neste platô máximo até ao redor das $14 \mathrm{~h}$ e decaindo no sentido do fim do dia (Figura 5A,D). No início da manhã até ao redor de 14 h, o aumento de $A$ ocorreu em função do aumento da DFFFA (Figuras 4 e 5). Entre aproximadamente 11 e $14 \mathrm{~h}$, quando $D F F F A$ máximo foi ao redor de $2000 \mu \mathrm{mol} \mathrm{m}^{-2} \mathrm{~s}^{-1}$, $A$ permaneceu com valores máximos decaindo posteriormente, com a queda de DFFFA. O valor máximo verificado foi de aproximadamente $48 \mu \mathrm{mol} \mathrm{m} \mathrm{m}^{-2} \mathrm{~s}^{-1}$ no estádio $\mathrm{V}_{8}$, e em $\mathrm{V}_{\mathrm{T}}, A$ máximo foi menor ao redor de $40 \mu \mathrm{mol}$ $\mathrm{m}^{-2} \mathrm{~s}^{-1}$ (Figura 5A,D). O menor valor de $A$ em $\mathrm{V}_{\mathrm{T}}$ em relação $V_{8}$ pode ser conseqüência do déficit hídrico no solo (Figura 1). A primeira reação da planta à ocorrência da deficiência hídrica é o fechamento parcial dos estômatos, causando queda em $g s$ (FLEXAs et al., 2006), como foi observado no estádio $\mathrm{V}_{\mathrm{T}}$ (Figura 5E).

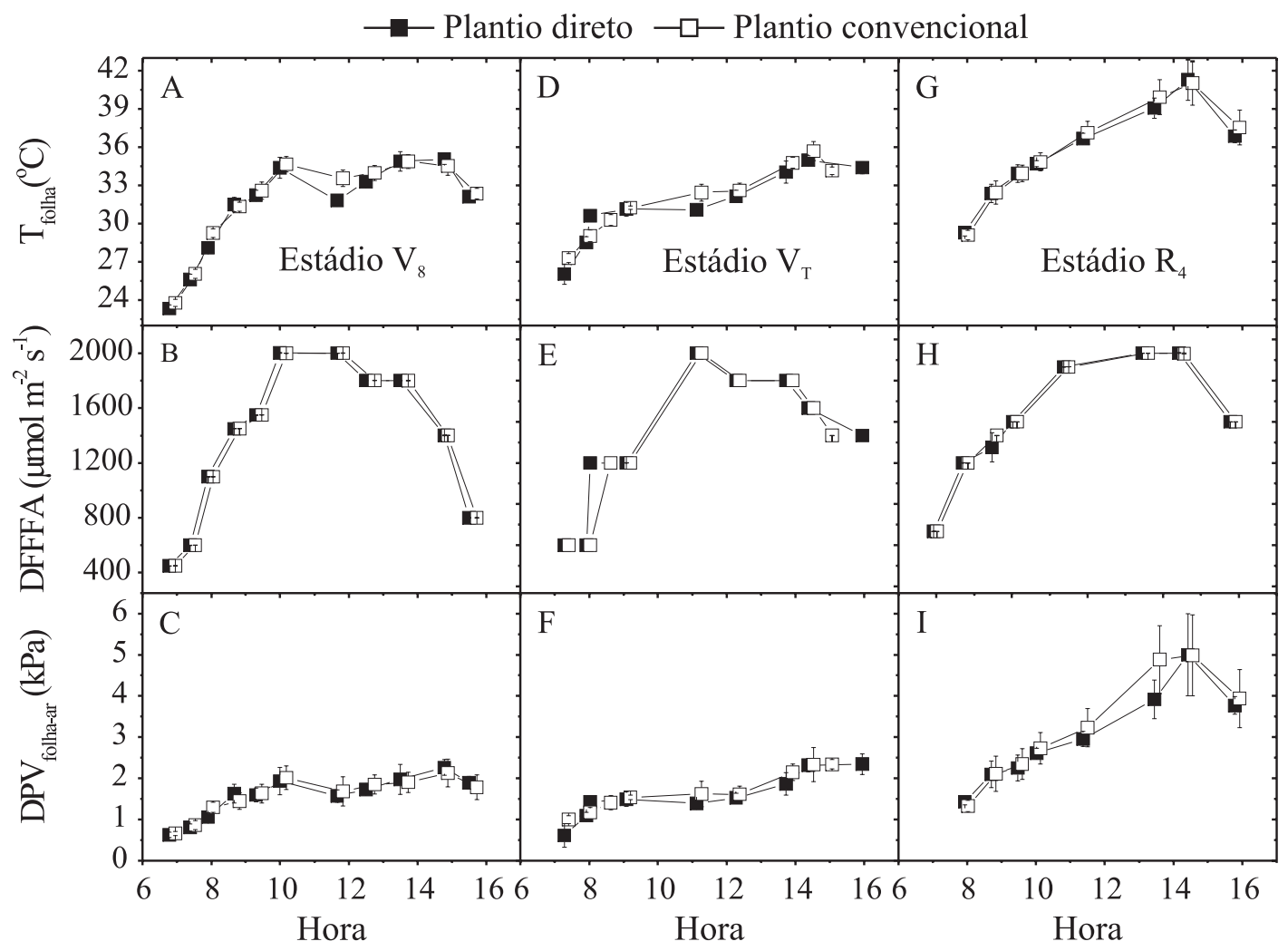

Figura 4. Variação diurna da temperatura da folha ( $T_{\text {folha }}, A, D$ e $\left.G\right)$, densidade de fluxo de fótons fotossinteticamente ativos $\left(D F F F A, \mathrm{~B}, \mathrm{E}\right.$ e H) e diferença de pressão de vapor entre a folha e o ar $\left(D P V_{\text {folha-ar, }} \mathrm{C}, \mathrm{F}\right.$ e I)) em milho híbrido IAC-8333 cultivado no sistema de plantio direto $(\boldsymbol{\square})$ e convencional $(\square)$, nos estádios de crescimento vegetativo, $\mathrm{V}_{8}$ (A, B e C em 24/1/2007); pendoamento, $V_{T}\left(D, E\right.$ e F em 7/2/2007) e crescimento dos grãos, $R_{4}(G, H$ e I em $8 / 3 /$ 2007). Linhas verticais indicam desvio-padrão relativo a cinco repetições. 


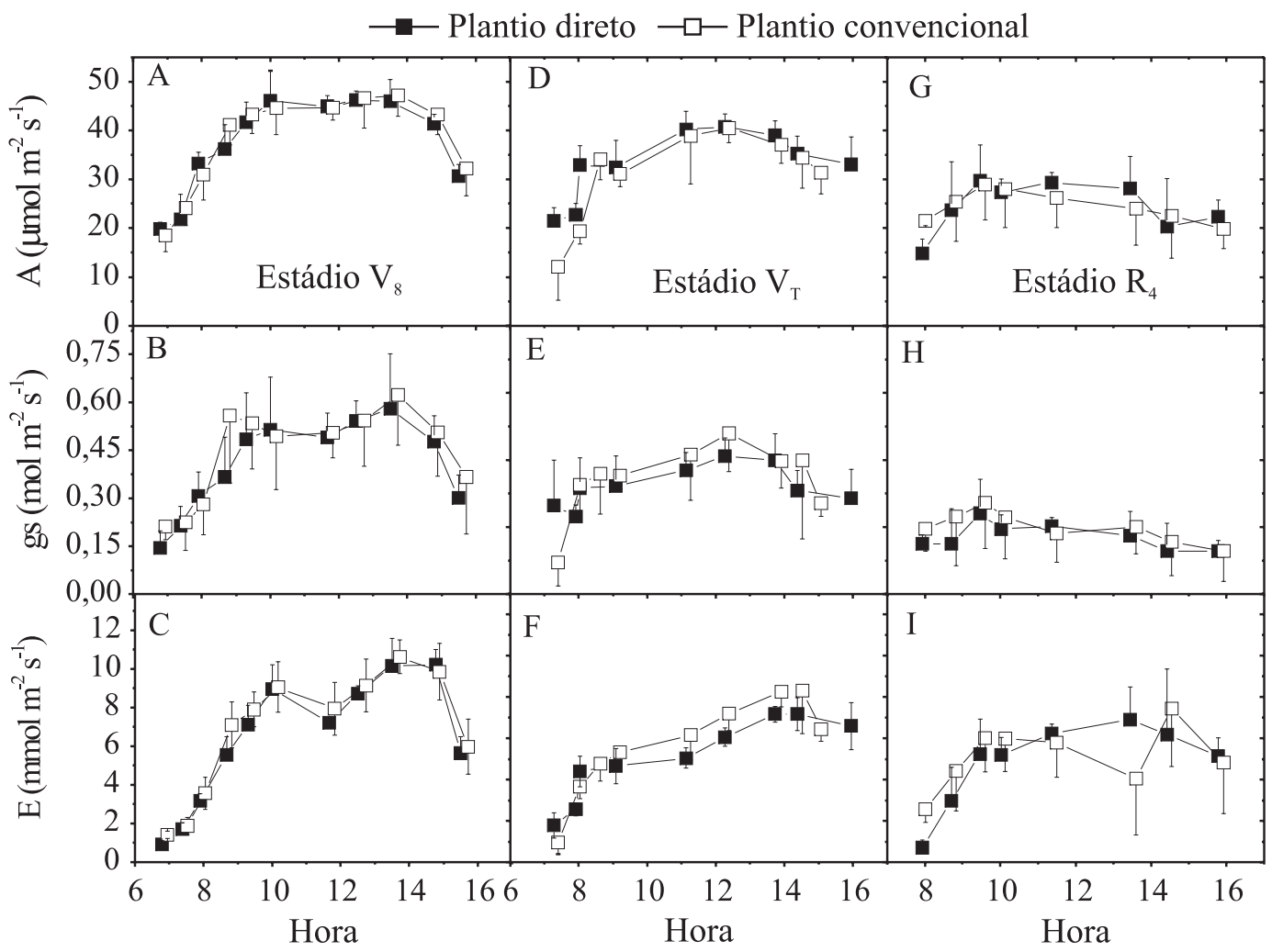

Figura 5. Variação diurna assimilação de $\mathrm{CO}_{2}(A$ em A, D e G), condutância estomática ( $g$ s em B, E e H) e transpiração $(E$ em $C, F$ e I)) em milho híbrido IAC-8333 cultivado no sistema de plantio direto ( $\boldsymbol{\square})$ e convencional ( $\square$ ), nos estádios de crescimento vegetativo, $\mathrm{V}_{8}$ (A, B e C em 24/1/2007); pendoamento, $\mathrm{V}_{\mathrm{T}}$ (D, E e F em 7/2/2007) e crescimento dos grãos, $R_{4}$ (G, H e I em 8/3/2007). Linhas verticais indicam desvio-padrão relativo a cinco repetições.

No período de enchimento de grãos $\left(\mathrm{R}_{4}\right), A$ máximo ocorreu ao redor das $9 \mathrm{~h}$ quando DFFFA era ao redor de $1200 \mu \mathrm{mol} \mathrm{m} \mathrm{m}^{-2} \mathrm{~s}^{-1}$ (Figuras 4 e 5) e a temperatura mais amena no início da manhã. Após às $9 \mathrm{~h}$ com o aumento da demanda evaporativa $\left(D P V_{a r}\right.$ folha) e em função do aumento da temperatura (Figura 4) os incrementos em DFFFA não causaram aumento em $A$, ocorrendo também saturação lumínica. MACHADO et al. (1992) também observaram saturação lumínica e queda em $A$ nos horários mais quentes do dia em dois híbridos de milho submetidos ao estresse hídrico. Em geral, nas plantas C4 como o milho, não há saturação lumínica na fotossíntese. Possivelmente a queda de $A$ foi devida à queda em $g s$, pois a transpiração deve ter sido maior que a capacidade de reposição de água às folhas pelo sistema radicular, devido ao déficit hídrico (Figura 1). Além da saturação lumínica, o valor máximo foi menor, ao redor de 30 $\mu \mathrm{mol} \mathrm{m} \mathrm{m}^{-2}$.

Na condutância estomática também houve variação diurna significativa, sendo os maiores valores observados normalmente durante a manhã, não importando a data de avaliação (Figura 5B,E,H). Esse padrão de variação de gs está relacionado à variação dos fatores ambientais, em especial a DFFFA e $D P V_{\text {folha-ar }}$ (Figuras 4 e 5), sendo a influência da temperatura foliar considerada nesse último. A abertura estomática foi crescente com o aumento de DFFFA, porém de forma característica para cada estádio fisiológico relativo à medida. No estádio vegetativo $\left(\mathrm{V}_{8}\right)$ gs aumentou até 0,6 $\mathrm{mol} \mathrm{m} \mathrm{m}^{-2}$ com DFFFA até valores próximos a 1500 $\mu \mathrm{mol} \mathrm{m} \mathrm{m}^{-2} \mathrm{~s}^{-1}$, quando então a saturação luminosa foi atingida, concordando com os valores citados por MACHADO et al. (1992) também em milho. Na segunda e terceira séries de medidas, nos estádios $\mathrm{V}_{\mathrm{T}}$ e $\mathrm{R}_{4}, g s$ já atingiu seu valor máximo ao redor das $8 \mathrm{~h} 30,0,45$ e 0,2 mol m $\mathrm{m}^{-2} \mathrm{~s}^{-1}$, respectivamente, quando DFFFA foi ao redor de $1200 \mu \mathrm{mol} \mathrm{m}^{-2} \mathrm{~s}^{-1}$. Os menores valores de $g s$ em $\mathrm{V}_{\mathrm{T}}$ e $\mathrm{R}_{4}$ estão relacionados, em parte à ocorrência de déficit hídrico ameno no solo (Figura 1). Mas em $\mathrm{R}_{4}$, onde o valor de $g s$ foi bem menor, além do déficit hídrico deve ter contribuído com a queda de gs a ocorrência de maior temperatura da folhas e conseqüente aumento de $D P V_{\text {folha-ar }}$ (Figuras $4 \mathrm{I}$ e $5 \mathrm{H}$ ). O aumento de $D P V_{\text {folha-ar }}$ em geral causa uma queda significativa em $g s$ em várias espécies (FARQUHAR e SharkeY, 1982; Habermann et al., 2003; FleXas et al., 2006). 
A queda de $A$ pode ainda estar relacionada a fatores fisiológicos, como início de senescência, variação da respiração, na eficiência quântica e em gs entre outros (DWYER e Stewart, 1986; STIRLING et al., 1994). Há relatos na literatura de que, sem estresses abióticos, $A$ é maior na fase de floração e/ou de crescimento linear de grãos em relação ao crescimento vegetativo, em função de maior demanda dos drenos (DWyer e Stewart, 1986; Dwyer et al., 1989; MAchado et al., 1994). Também há relatos de que a máxima fotossíntese é atingida ao redor de uma semana após a expansão máxima da folha (DWYER et al., 1989). No entanto, também há autores que não observam esta resposta (RAWSON et al., 1978). Tais controvérsias podem estar relacionadas às demais condições ambientais em que foram executadas as medidas. Os trabalhos citados, assim como o nosso, foram executados em condições de campo, onde vários fatores agem concomitantemente. Assim, no caso presente à queda de $A$ no sentido da fase vegetativa $\left(\mathrm{V}_{8}\right)$ para fase de floração $\left(\mathrm{V}_{\mathrm{T}}\right)$ e enchimento de grãos $\left(R_{4}\right)$ deve estar relacionada com a ocorrência de déficit hídrico (Figura 1). Tal resposta é justificada pelo fechamento parcial dos estômatos observada em $\mathrm{V}_{\mathrm{T}} \mathrm{e}$ $\mathrm{R}_{4}$. A maior queda de $A$, principalmente no período de enchimento dos grãos $\left(\mathrm{R}_{4}\right)$ além dos aspectos ambientais, como déficit hídrico e alta temperatura, pode ter sido influenciado ainda pela idade da folha, no entanto, por todas estarem agindo concomitantemente é difícil apontar um fator específico.

A transpiração também seguiu um padrão semelhante de resposta em função da hora do dia, e seus valores máximos ocorreram ao redor das $14 \mathrm{~h}$, quando gs e $D P V_{\text {folha-ar }}$ também eram máximos. Assim, além de $g s$ ter atingido seu valor máximo mais cedo isto ocorreu em DFFFA mais baixo (Vu et al., 1986). Os valores máximos de $E$ ficaram próximos a $10 \mathrm{mmol}$ $\mathrm{m}^{-2} \mathrm{~s}^{-1}$ em $\mathrm{V}_{8}$ e ao redor de $8 \mathrm{mmol} \mathrm{m}^{-2} \mathrm{~s}^{-1}$ em $\mathrm{V}_{\mathrm{T}}$ e $\mathrm{R}_{4}$. Não houve queda de $E$ da segunda para a terceira fase apesar da queda em $g s$, pois $D P V_{\text {folha-ar }}$ mais elevado na terceira fase compensou parcialmente a menor abertura estomática. A transpiração é dependente tanto da abertura estomática como do $D P V_{\text {folha-ar }}$ (DAI et al., 1992; MACHADO et al., 1992).

\section{CONCLUSÕES}

1. Os maiores acúmulos de fitomassa total e de espigas e produção de grãos no sistema de plantio convencional são devidos ao estabelecimento mais rápido de um índice de área foliar maior.

2. O maior índice de área foliar proporciona maior taxa de crescimento da cultura de milho em plantio convencional.
3. O sistema de plantio na cultura do milho não afeta as trocas gasosas.

\section{REFERÊNCIAS}

BEADLE, C.L. Growth analysis. In: HALL, D.O.; SCURLOCK, J.M.O.; BOLHAR-NORDENKAMPF, H.R.; LEEGOOD, R.C.; LONG, S.P. (eds.). Photosynthesis and production in a changing environment. A field and laboratory manual. London: Chapman \& Hall, 1993 p.36-46.

CARVALHO, M.A.C.; SORATTO, R.P.; ATHAYDE, M.L.F. Produtividade do milho em sucessão a adubos verdes no sistema de plantio direto e convencional. Pesquisa Agropecuária Brasileira, v.39, p.47-53, 2004.

CENTURION, J.F.; DEMATTÊ, J.L.I. Efeitos de sistemas de preparo nas propriedades físicas de um solo sob cerrado cultivado com soja. Revista Brasileira de Ciência do Solo, v.9, p.263-266, 1985.

COX, W.J.; ZOBEL, R.W.; VAN ES, H.M.; OTIS, D.J. Tillage effects on some soil physical and corn physiological characteristics. Agronomy Journal, v.82, p.806-85, 1990.

DAI, Z.; EDWARD, G.E.; KU, M.S.B. Control of photosynthesis and stomatal conductance in Ricinus communis L. (Castor bean) by leaf to air vapor pressure deficit. Plant Physiology, v.99, p.1426-1434, 1992.

DWYER, L.M.; STEWART, D.W. Effets of leaf age and position on net photosynthesis rate in maize. Agricultural and Foresty Meteorology, v.37, p.29-46, 1986.

DWYER, L.M.; STEWART, D.W.; BAICHIN, D.; HOUWING, L.; MARUR, C.J.; HAMILTON, R.I. Photosynthesis rates of six maize cultivars during development. Agronomy Journal, v.81, p.597-602, 1989 .

EMBRAPA - Centro Nacional de Pesquisa de Solos. Sistema Brasileiro de Classificação de Solos. Rio de Janeiro, 1999. 45 p.

FARQUHAR, G.D.; SCHULZE, E.D.; KÜPPER, M. Response to humidity by stomata of Nicotina glauca L. and Corylus avellana L. are consistent with optimization of carbon dioxide uptake with respect to water loss. Australian Journal of Plant Physiology, v.7, p.315-327, 1980.

FARQUHAR, G.D.;SHARKEY, T.D. Estomatal conductance and photosynthesis. Annual Review of Plant Physiology, v.33, p.317-345, 1982.

FLEXAS, J.; BOTA, J.; GALMÉS, J.; MEDRADO, H.; RIBASCARBÓ, M. Keeping a positive carbon balance under adverse conditions: responses of photosynthesis and respiration to water stress. Physilogia Plantarum, v.57, p.343-352, 2006.

HABERMANN, G.; MACHADO, E.C.; RODRIGUES, J.D.; MEDINA, C.L. $\mathrm{CO}_{2}$ assimilation, photosynthetic light response curvas, and water relations of "Pera" sweet oranges plants infected with Xilella fastidiosa. Brazilian Journal of Plant Physiology, v.15, p.79-87, 2003. 
HERNANI, L.C.; SALTON, J.C. Milho: informações técnicas. Centro de Pesquisa Agropecuária do Oeste. Manejo e conservação de solos. Dourados, EMBRAPA/CPAO, 1997. p.3967. (Circular técnica, 05)

HILL, R.L. Long term conventional and no-tillage effects on selected soil physical properties. Soil Science Society American Journal, v.54, p.161-166, 1990.

ISMAIL, I.; BLEVINS, R.L.; FRYE, W.W. Long-term no-tillage effects on soil properties and continuous corn yields. Soil Science Society American Journal, v.58, p.193-198, 1994.

MACHADO, E.C; PEREIRA, A.R.; FAHL, J.I.; ARRUDA, H.V.; SILVA, W.J. da.; TEIXEIRA, J.P.F. Análise quantitativa de crescimento de quatro variedades de milho em três densidades. Pesquisa Agropecuária Brasileira, v.17, p.825-833, 1982.

MACHADO, E.C.; FURLANI, P.R.; HANNA, L.G.; CAMARGO, M.B.P.; BRUNINI, O.; MAGALHÃES, H.H.S. Características biométricas e fisiológicas de três variedades de milho. Bragantia, v.44, p.283-294, 1985.

MACHADO, E.C.;SILVEIRA, J.A.G. da; BASTOS, C.R. Trocas de $\mathrm{CO}_{2}$, acúmulo de fitomassa e remobilização de reservas durante o crescimento de panículas de duas variedades de arroz. Revista Brasileira de Fisiologia Vegetal, v.2, p.63-70, 1990.

MACHADO, E.C.; SILVEIRA, J.A.G.; VITORELLO, V.A. ; RODRIGUES, J.D. Fotossíntese, remobilização de reservas e crescimento de grãos em dois cultivares de milho sob deficiência hídrica. Bragantia, v. 51, p. 151-159, 1992.

MACHADO, E.C.; LAGÔA, A.M.M.A.; TICELLI, M.; AZZINI, L.E.; TISSELLI FILHO, O. Fotossíntese e crescimento de panículas de arroz de sequeiro (Oryza sativa L.). Revista Brasileira de Botânica, v.17, p.37-43, 1994.

MAGALHÃES, P.C.; DURÃES, F.O.M.; CARNEIRO, N.P.; PAIVA, E. Fisiologia do milho. 1.ed. Sete Lagoas: Ministério da Agricultura, Pecuária e Abastecimento, 2003. 23p. 2003 (Circular Técnica n. ${ }^{\circ} 22$ )

MELO, J.F.; SILVA, J.R.C. Erosão, teor de água no solo e produtividade do milho em plantio direto e preparo convencional de um podzólico vermelho-amarelo no Ceará. Revista Brasileira de Ciências do Solo, v.17, p.291-297, 1993.

PAULETTI, V.; LIMA, M.R. de; BARCIK, C; BITTENCOURT, A. Rendimento de grãos de milho e soja em uma sucessão cultural de oito anos sob diferentes sistemas de manejo de solo e de culturas. Ciência Rural, v.33, p.491-495. 2003.

PEDERSEN, P.; LAUER, J.G. Corn and soybean response to rotation sequence, row spacing and tillage system. Agronomy Journal, v.95, p.965-971, 2003.

PEREIRA, A.R.; MACHADO, E.C. Análise quantitativa do crescimento de comunidades vegetais. Campinas: Instituto Agronômico 1987. 33p. (Boletim Técnico, 44)

QIN, R.; STAMP, P.; RICHNER, W. Impact of tillage and banded starter fertilizer on maize root growth in the top 25 centimeters of the soil. Agronomy Journal, v.97, p.674-683, 2005.
RAWSON, H.M.; TURNER, N.C.; BEGG, J.E. Agronomic and physiological responses of soybean and sorghum crops to water deficits. IV. Photosynthesis, transpiration and water use efficiency of leaves. Australian Journal Plant Physiology, v.5, p.179-194, 1978.

ROLIM, G.S.; SENTELHAS, P.C.; BARBIERI, V. Planilhas no ambiente Excel ${ }^{\mathrm{TM}}$ para os cálculos de balanços hídricos: normal, seqüencial, de cultura e de produtividade real e potencial. Revista Brasileira de Agrometeorologia, v.6, p. 133-137, 1998.

SECCO, D.; DA ROS, C.O.; SECCO, J.K.; FIORIN, J.E. Atributos físicos e produtividade de culturas em um latossolo vermelho argiloso sob diferentes sistemas de manejo. Revista Brasileira de Ciência do Solo, v.29, p.407-414, 2005.

SETZER, J. Atlas climático e ecológico do Estado de São Paulo. São Paulo: Comissão Interestadual da Bacia Paraná-Uruguai. 1966. 61p.

SILVEIRA, P.M.; STONE, L.F. Sistemas de preparo do solo e rotação de culturas na produtividade de milho, soja e trigo. Revista Brasileira de Engenharia Agrícola e Ambiental, v.7, p.240-244, 2003.

SINGER, J.W.; LOGSDON, S.D.; MEEK, D.W. Tillage and compost effects on corn growth, nutrient accumulation, and grain yield. Agronomy Journal, v.99, p.80-87, 2007.

STIRLING, C.M.; AGUILERA, C.; BAKER, N.R.; LONG, S.P. Changes in the photosynthetic light response curve during leaf development of field grown maize with implications for modelling canopy photosynthesis. Photosynthesis Research, v.42, p.217-225, 1994.

URCHEI, M.A.; RODRIGUES, J.D.; STONE, L.F. Análise de crescimento de duas cultivares de feijoeiro, sob irrigação em plantio direto e preparo convencional. Pesquisa Agropecuária Brasileira, v.35, p.497-506, 2000.

VU, J.C.V.; YELENOSKY, G.; BAUSHER, M.G. $\mathrm{CO}_{2}$ exchange rate, stomatal conductance, and transpiration in attached leaves of 'Valencia' orange. HortScience, v.21, p.143-144, 1986.

YUSUF, R.I.; SIEMENS, J.C.; BULLOCK, D.G. Growth analysis of soybean under no-tillage and conventional tillage systems. Agronomy Journal, v.91, p. 928-933, 1999. 